5. Young RH, Koelliker DD, Scully RE. Sertoli cell tumors of the testis, not otherwise specified. A clinicopathologic analysis of 60 cases. Am J Surg Path. 1998;22:709-21.

6. Zukerberg LR, Young RH, Scully RE. Sclerosing Sertoli Cell Tumor of the Testis. A Report of 10 cases. Am J Surg Pathol. 1991;15:829-34.

7. Carney JA, Gordon H, Carpenter PC, Shenoy BV, Go VLW. The complex of myxomas, spotty pigmentation and endocrine overactivity. Medicine. 1985;64:270-83.

8. Gabrilove JL, Freiberg EK, Leiter E, Nicolis GL. Feminizing and nonfeminizing Sertoli cell tumors. J Urol. 1980;124:757-67.
C.J. Yánez Benítez ${ }^{\mathrm{a}, *}$, C. Valero Valdivieso ${ }^{\mathrm{a}}$, J.I. Sanz Vélez ${ }^{b}$ y M. Marigil Gómez ${ }^{\mathrm{c}}$

${ }^{a}$ Servicio de Cirugía General y del Aparato Digestivo, Hospital San Jorge, Huesca, España

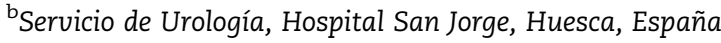

'Servicio de Anatomía Patológica, Hospital San Jorge, Huesca, España

*Autor para correspondencia.

Correo electrónico: carlosyb1@gmail.com (C.J. Yánez Benítez).

\title{
Pólipo fibroepitelial ureteral gigante resuelto con resección y sustitución intestinal
}

\author{
Giant fibroepithelial polyp of the ureter: treatment with ureteral \\ resection and intestinal substitution
}

\section{Sr. Director:}

Los pólipos fibroepiteliales del uréter son raros tumores mesenquimales. El primer caso fue descrito por Boross en 19291. Debido a su naturaleza benigna la mayoría de los autores recomiendan cirugía conservadora con técnicas mínimamente invasivas aunque en ocasiones debido al tamaño y localización del pólipo es necesario recurrir a la cirugía abierta.

Presentamos el caso de una mujer de 42 años sin antecedentes de interés que sufre cuadro de cólico renal izquierdo. En ecografía se aprecia hidronefrosis izquierda sin identificar la causa. La urografía intravenosa (fig. 1) revela retraso funcional de riñón izquierdo y ureterohidronefrosis severa hasta uréter ilíaco con numerosos pliegues. El TAC y la $\mathrm{RM}$ informan de un posible tumor en uréter izquierdo. La práctica de una ureteroscopia no fue concluyente por grandes dificultades de interpretación de los hallazgos tomándose biopsia de mucosa ureteral que demostró un urotelio normal con ligero edema e inflamación del corion subyacente. La citología urinaria fue negativa.

Se decide practicar exploración quirúrgica mediante laparotomía media en la que se muestra el uréter izquierdo ocupado por una tumoración de consistencia blanda de varios centímetros de grosor desde el cruce de los vasos ilíacos hasta el uréter yuxtapiélico (fig. 2), por lo que se decidió resecar todo el segmento ureteral afectado enviándolo para evaluación anatomopatológica intraoperatoria para decidir actitud sobre la unidad renal.

El informe intraoperatorio fue de pólipo fibroepitelial por lo que para conservar el riñón se decidió utilizar segmento ileal de sustitución. El estudio anatomopatológico definitivo confirma el diagnóstico de pólipo fibroepitelial ureteral.

La urografía intravenosa de control a los dos meses evidencia una mejoría de la dilatación y de la función del sistema excretor izquierdo, estando la paciente asintomática.
Los tumores del uréter no son frecuentes y representan menos del $1 \%$ de todos los tumores genitourinarios. Sólo el $20 \%$ de ellos son benignos y el pólipo fibroepitelial es el más frecuente ${ }^{2}$. Los tumores ureterales benignos pueden ser epiteliales o no epiteliales, originándose estos últimos a partir de elementos mesodérmicos de la pared ureteral y pueden corresponder a leiomiomas, fibroepiteliomas, linfangiomas, neurofibromas, hemangiomas, endometriomas, fibromas y pólipos fibroepiteliales ${ }^{1}$.

Generalmente tienen un origen congénito o inflamatorio aunque su etiología no ha quedado bien establecida. La mayoría son pólipos pequeños aunque también se han descrito lesiones de gran tamaño. A menudo son pólipos únicos aunque en ocasiones pueden ser múltiples.

Macroscópicamente se tratan de proyecciones filiformes que van desde pocos milímetros hasta poder alcanzar varios centímetros. En el estudio anatomopatológico se identifican como un grueso tallo fibroso con numerosos canales vasculares cubiertos por una capa de epitelio transicional normal o hiperplásico ${ }^{3}$.

Aunque pueden aparecer en cualquier etapa de la vida lo habitual es que afecten a adultos entre la tercera y quinta década de la vida y con predominio en el sexo masculino ${ }^{1}$. Son más frecuentes en el lado izquierdo y se pueden localizar en cualquier punto del uréter aunque predominan en el tercio superior.

La sintomatología consiste en dolor en el flanco o abdominal, infección del tracto urinario y macro microhematuria, sufriendo nuestra paciente dolor por uropatía obstructiva.

Las técnicas radiológicas no permiten distinguirlos de los tumores malignos de células transicionales y en ocasiones pueden dar falsos positivos en la citología urinaria ${ }^{4}$, no ocurrió así en nuestro caso, por lo que históricamente muchos pacientes eran sometidos innecesariamente a nefroureterectomías ${ }^{5}$. Por tanto la ureteroscopia con biopsia se considera el mejor procedimiento para el diagnóstico ${ }^{6}$, aunque en el caso clínico presentado no fuera concluyente. 


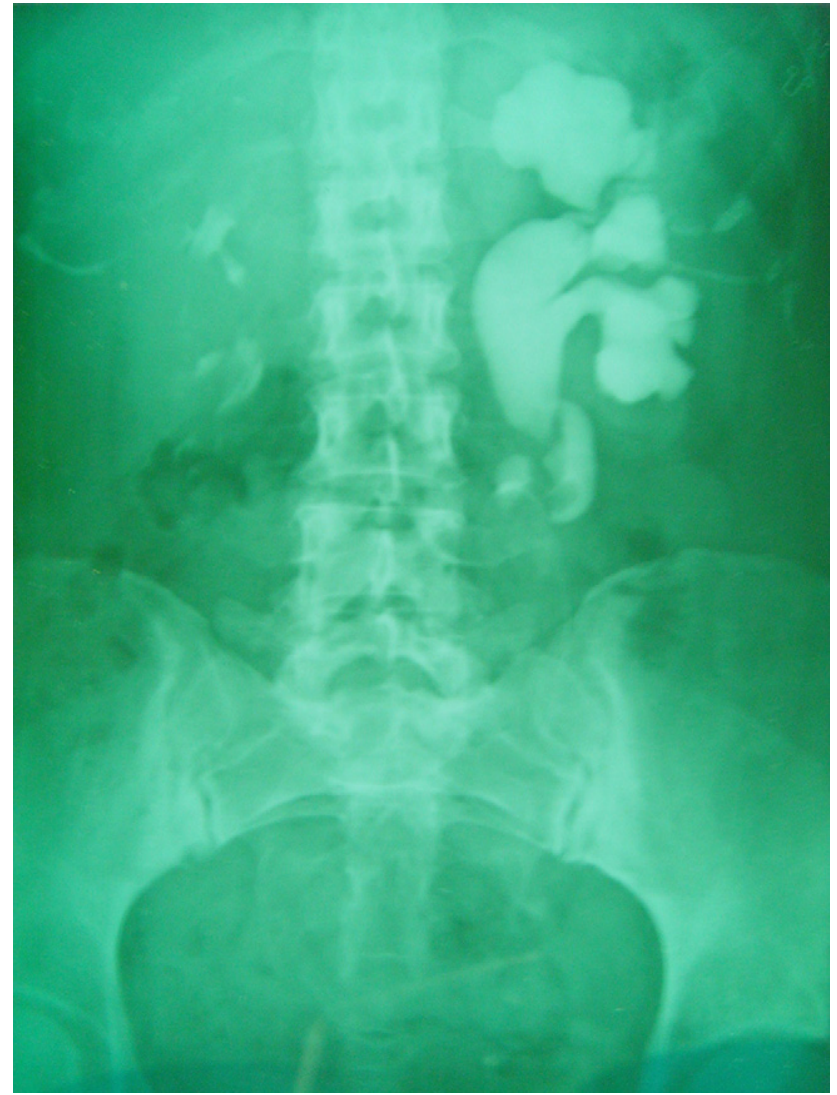

Figura 1 - Urografía intravenosa con ureteropielocaliectasia izquierda con uréter engrosado y tortuoso.

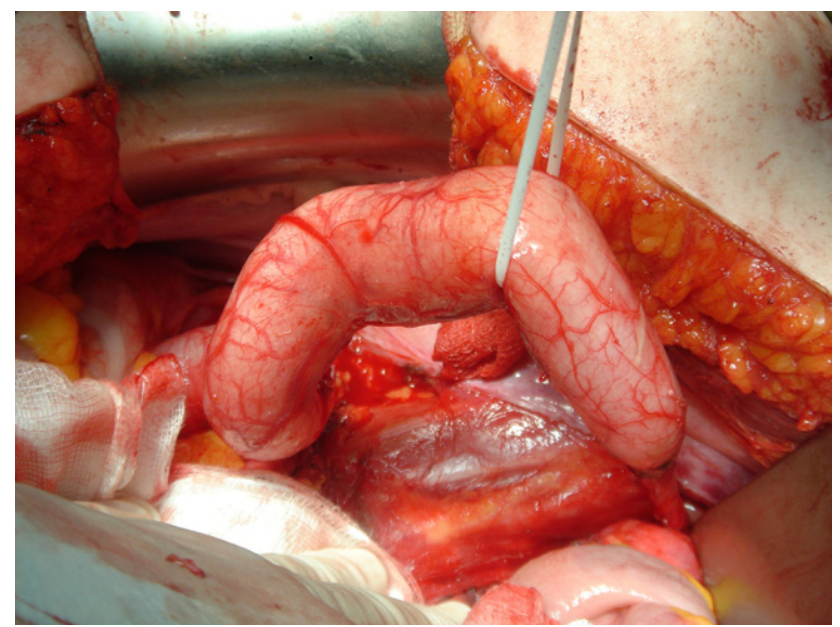

Figura 2 - Detalle quirúrgico de pólipo fibroepitelial ureteral con extremo distal sano.

En la actualidad las técnicas mínimamente invasivas están en auge recomendándose como tratamiento la resección transuretral con el ureteroscopio ${ }^{7}$ pudiendo emplearse el acceso percutáneo ${ }^{8}$ o realizar la exéresis de la lesión con el láser Holmiun ${ }^{9}$; recientemente se ha utilizado por primera vez la laparoscopia en el tratamiento de un pólipo ureteral de gran tamaño ${ }^{10}$.

En los casos en los que el abordaje endoscópico se considere inaccesible, como así nos sucedió, habrá que recurrir a la cirugía abierta, y dentro de los procedimientos quirúrgicos descritos se encuentran en función de la localización y tamaño del pólipo, la resección pieloureteral con pieloplastia de Anderson-Hynes, la resección ureteral con anastomosis termino terminal o con sustitución intestinal y la resección ureteral con autotrasplante renal $^{6}$ quedando reservada la nefroureterectomía en los casos en los que el riñón ha perdido su funcionalidad.

La recurrencia de la lesión tras polipectomía o resección ureteral todavía no hay sido descrita teniendo muy buen pronóstico $^{1}$.

B I B L I O G R A F Í A

1. Rigabert Montiel M, Martínez Barba E, López Cubillana $P$, Nicolás Torralba JA, Bañón Pérez JV, Valdelvira Nadal P, et al. Giant fibroepithelial polyp of the ureter. Arch Esp Urol. 2000;53:940-3.

2. Tato Rodríguez J, Lema Grille J, Cimadevila García A, Blanco Parra M, Lamas Cedrón P, Ríos Tallón L, et al. Fibroepithelial polyp of the ureter. A report of 2 new cases. Actas Urol Esp. 1997;21:420-5.

3. Camacho García C, Martín Betancort D, Díaz Iglesia JM, García Serrano C, Chesa Ponce N, Báez Marrero O. A fibroepithelial myxoid polyp of the renal pelvis in a patient with horseshoe kidneys. Apropos a case. Actas Urol Esp. 1999;23:609-12.

4. Psihramis KE, Hartwick W. Ureteral fibroepithelial polyp with positive urinary cytology. Urology. 1993;41:387-91.

5. Faerber GJ, Ahmed MM, Marcovich R, Crisco CP, Belville WD. Contemporary diagnosis and treatment of fibroepithelial ureteral polyp. J Endourol. 1997;11:349-51.

6. Zeman L, Dusek M, Lisy J, Moravek J, Rygl M, Stejskal J, et al. Multiple fibroepithelial polyps of the upper ureter in a 17-year-old boy-case. Report and review of the literature. Eur J Pediatr Surg. 2004;14:358-61.

7. Segawa N, Abe H, Nishida T, Katsuoka Y. Ureteral polyp occurring as renal dysfunction with contralateral ureteral calculi: a case report. Hinyokika Kiyo. 2005;51:451-3.

8. Lam JS, Bingham JB, Gupta M. Endoscopic treatment of fibroepithelial polyps of the renal pelvis and ureter. Urology. 2003;62:810-3.

9. Yagi S, Kawano Y, Gotanda T, Kitagawa T, Kawahara M, Nakagawa $\mathrm{M}$, et al. Endoscopic treatment of a long fibroepithelial ureteral polyp. J Urol. 2001;8:467-9.

10. Kijvikai K, Maynes LJ, Herrell SD. Laparoscopic management of large ureteral fibroepithelial polyp. Urology. 2007;70:373.e4-7.

F. Vázquez-Alonso*, F.J. Rodríguez-Herrera, C. Funes-Padilla y J.M. Cózar-Olmo

Servicio de Urología del Hospital Universitario Virgen de las Nieves, Granada, España

Autor para correspondencia.

Correo electrónico: fernando.vazquez.alonso.sspa@ juntadeandalucia.es (F. Vázquez-Alonso). 